\title{
Preparation of $\mathrm{TiO}_{2}$ Thin Film Photocatalyst by High-rate Low-temperature Sputtering Method*
}

\author{
Daisuke NOGUCHI*1, Kana OKUTSU*1, Saori ONITSUKA*1, Yoshihiko KAWANO*2 and Fumihiro SEI*2 \\ ${ }^{*}$ Department of Chemical Science and Engineering, Miyakonojo National College of Technology, 473-1 Yoshio-cho, \\ Miyakonojo, Miyazaki 885-8567, Japan \\ ${ }^{*}$ Honda Lock Mfg, 3700 Shimonaka, Sadawara-cho, Miyazaki 880-0293, Japan
}

(Received July 27, 2009, Accepted November 14, 2009)

\begin{abstract}
After depositing an ultra-thin metallic Ti film by sputtering, we repeated the process of exposing the still active plasma gas for high-rate low-temperature deposition of a metal compound film, thereby successfully fabricating a thin film of $\mathrm{TiO}_{2}$ with photocatalytic properties. The $\mathrm{TiO}_{2}$ thin film produced using the present method exhibited approximately 15 times the deposition rate of DC reactive magnetron sputtering, yielding a crystalline structure using an unheated substrate (approximately $\left.40^{\circ} \mathrm{C}\right)$.
\end{abstract}

\section{Introduction}

Numerous products that utilize the superior photocatalytic activity of photocatalytic Titanium oxide $\left(\mathrm{TiO}_{2}\right)$ are being developed ${ }^{1-3)}$. With the current increased attention to environmental issues, demand for such products is expected to continually increase. In the cases when $\mathrm{TiO}_{2}$ is used as a photocatalyst, it typically needs to be attached to some base material. Establishing this immobilization technology for a photocatalyst appropriate for a specific product is arguably the most important factor in the development of photocatalytic materials. From a practical perspective, in order to form a $\mathrm{TiO}_{2}$ film as a photocatalyst on a substrate such as glass, Sol-Gel ${ }^{4)}$ or vacuum evaporation ${ }^{5)}$ methods are currently used. More recently, sputtering has received particular attention for this application ${ }^{6-12)}$. An advantage of this method over other methods is that it is effective for forming high-quality thin films uniformly over large areas with control of the microstructure to some extent on an atomic level. However, for using Ar as the sputter gas and $\mathrm{O}_{2}$ as the reactive gas in actual DC reactive magnetron sputtering ${ }^{13)}$, since the flow of the reactive gas increases when the film is formed, the reduction in the deposition rate due to oxidation of the target surface is a problem. Also, technological problems expected in the future include the development of a process to reduce the deposition temperature below current levels, simplifying the equipment needed, improvements in throughput (e.g., deposition rate), and cost reduction.

Based on the above, in the present research, we attempted high-rate low-temperature deposition of $\mathrm{TiO}_{2}$ thin film photocatalyst using high-rate sputtering at a low temperature and compared this with conventional methods. The method used for forming metal compound

* 平成 20 年度 11 月 20 日 スパッタリングおよびプラズマプロセス 技術部会第 5 回技術交流会·第111回定例研究会で発表

*1 都城工業高等専門学校物質工学科 (厂885-8567 宮崎県都城市吉 尾町473-1)

*2 株式会社ホンダロック( 珂3700番地） films (such as oxide and nitride films) uses exposing the still active plasma gas and repeating the process of oxidation or nitriding after depositing an ultrathin film of metal on a substrate by sputtering.

\section{Experimental}

In the case of the $\mathrm{TiO}_{2}$ thin films produced by highrate low-temperature sputtering, we were able to obtain $\mathrm{TiO}_{2}$ photocatalyst thin film possessing a crystalline structure with the substrate unheated at deposition rates comparable to those for metal film. For forming the $\mathrm{TiO}_{2}$ thin films in this study, equipment specially constructed in our laboratory was used to allow implementation of high-rate low-temperature sputtering, by making modifications to a $\varphi 3$ in $\times 3$ sputter source and etching mechanism, standard equipment in RF multisource magnetron sputtering devices (CFS-4ES, made by Shibaura Mechatronics). The high-rate low-temperature sputtering deposition process is shown in Fig. 1. First, Ar gas is introduced with the target side potential as the cathode, and an ultra-thin film of metal accumulates on the substrate. Next, $\mathrm{O}_{2}$ gas is introduced with the substrate side potential as the cathode, and the ultra-thin metal film on the substrate is oxidized by irradiation with oxygen plasma, thereby producing the $\mathrm{TiO}_{2}$ thin film. This latter process is repeated to produce an oxidation layer of specified thickness. At this point, automatic sequence control was used to control the sputtering and oxidation processes, with sufficient consideration given to repeatability. Thus, by carrying out the high-rate low-temperature sputtering in two steps - the metal coating process and the thin film oxidation process - excessive target oxidation is avoided, and arcing of the metal coating due to sputtering is comparatively rare. An additional feature is that by dramatically shortening the irradiation time for both plasmas, increases in substrate temperature are prevented. Table 1 shows the deposition conditions used. Ti metal (99.99\% pure) was used as the target, Ar $(99.9999 \%)$ was used as the sputter gas, and $\mathrm{O}_{2}(99.9999$ $\%)$ as the reactive gas, with gas pressures of $1.5 \mathrm{~Pa}$ for Ar and 3.0 Pa for $\mathrm{O}_{2}$. The sputter output was $400 \mathrm{~W} \mathrm{DC}$, 


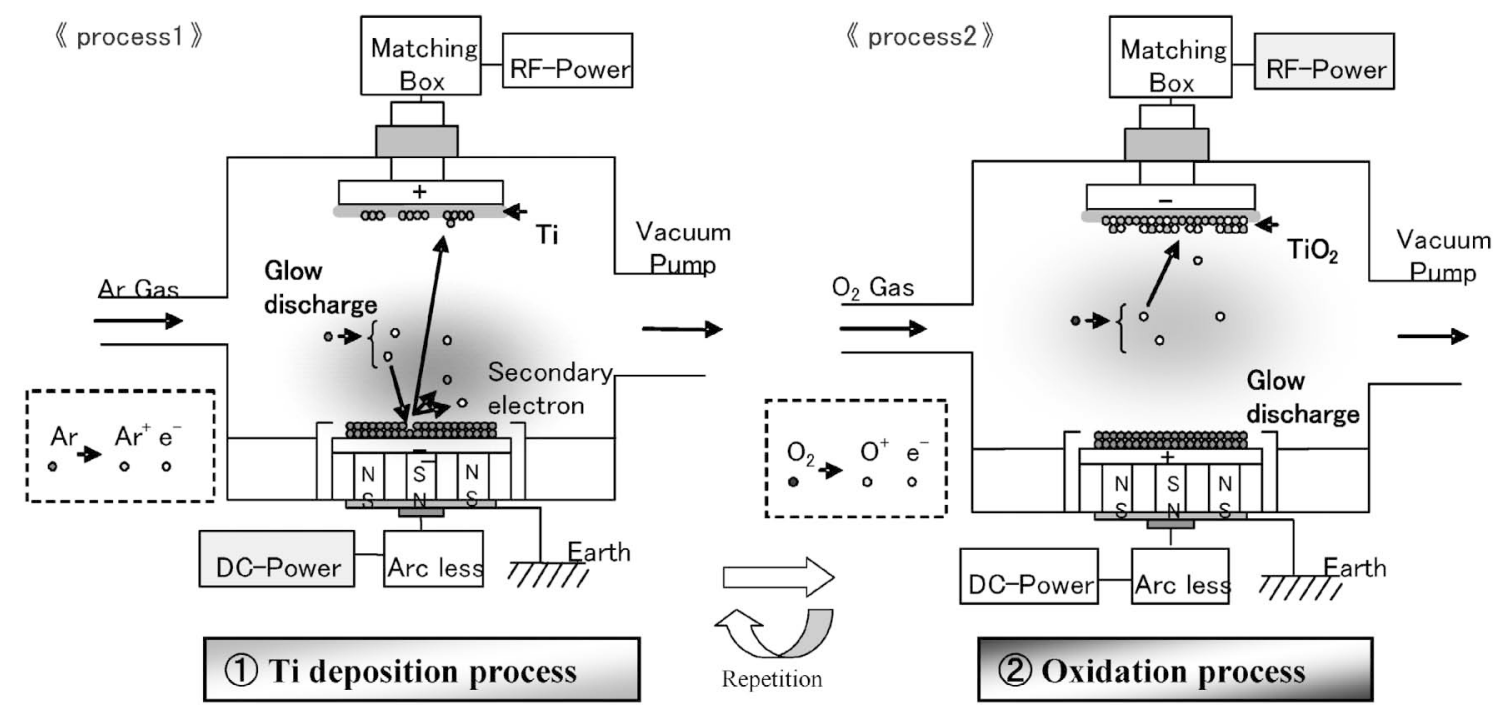

Fig. 1 High-rate low-temperature sputtering deposition process used in the present work.

Table $1 \quad \mathrm{TiO}_{2}$ thin films deposition conditions.

\begin{tabular}{|c|c|c|}
\hline Deposition & $\begin{array}{l}\text { High-rate low-tem- } \\
\text { perature sputtering }\end{array}$ & $\begin{array}{l}\text { DC reactive magne- } \\
\text { tron sputtering }\end{array}$ \\
\hline Sample & S1 & $\mathrm{S} 2$ \\
\hline DC power & $400 \mathrm{w}$ & $400 \mathrm{~W}$ \\
\hline Ti thickness/1-cycle & $1.0 \mathrm{~nm}$ & - \\
\hline Ar gas pressure & $1.5 \mathrm{~Pa}$ & $1.05 \mathrm{~Pa}$ \\
\hline RF power & $300 \mathrm{w}$ & - \\
\hline $\begin{array}{l}\text { Plasuma irradiation } \\
\text { time }\end{array}$ & $1.5 \mathrm{~s}$ & $7143 \mathrm{~s}$ \\
\hline $\mathrm{O}_{2}$ gas pressure & $3.0 \mathrm{~Pa}$ & $0.45 \mathrm{~Pa}$ \\
\hline Film thickness & $150 \mathrm{~nm}$ & $150 \mathrm{~nm}$ \\
\hline $\begin{array}{l}\text { Substrate tempera- } \\
\text { ture }\end{array}$ & 一 & $300^{\circ} \mathrm{C}$ \\
\hline Substrate & \multicolumn{2}{|c|}{ Soda-lime glass } \\
\hline
\end{tabular}

$300 \mathrm{~W}$ RF, and a $150 \mathrm{~nm}$ thick film was formed on unheated soda-lime glass substrates. The system was discharged until the back pressure dropped to under $8.0 \times$ $10^{-3} \mathrm{~Pa}$, and the gas pressure was controlled to a specified gas pressure during discharge using a diaphragm gauge. In addition, a $\mathrm{TiO}_{2}$ thin film was produced by DC reactive magnetron sputtering as a reference sample. Using Ti (99.99\% pure), a film was formed on the target in a mixed gas plasma of $\mathrm{Ar} / \mathrm{O}_{2}(70 / 30 \%)$ with a gas pressure of $1.5 \mathrm{~Pa}$ and a film thickness of $150 \mathrm{~nm}$ was obtained. The input power was $400 \mathrm{~W} \mathrm{DC}$, and the substrate temperature was $300^{\circ} \mathrm{C}$. The thickness of the deposited films were analyzed with an ellipsometer (DHA-FX Mizojiri Optical Co., Ltd.), and the crystal structure and surface morphology were analyzed using $\mathrm{X}$ ray diffraction (XRD: made by Rigaku, ATX-G) and scanning electron microscopy (FE-SEM: Hitachi, Ltd. S-900), respectively. Using ultraviolet irradiation from a black light (BL, Toshiba Lighting and Technology Corp.), the distance was adjusted so that the irradiation intensity was $1 \mathrm{~mW} / \mathrm{cm}^{2}$. Photoinduced hydrophilic conversion was evaluated by measuring the contact angle of pure water (Kyowa Interface Science Co., DM-300), and
Table 2 Comparison of deposition rates due to differences in the deposition method.

\begin{tabular}{ccc}
\hline \hline Sample & $\mathrm{S} 1$ & $\mathrm{~S} 2$ \\
\hline Rate $[\mathrm{nm} / \mathrm{s}]$ & 0.32 & 0.021 \\
\hline
\end{tabular}

photocatalytic activity was evaluated by measuring density changes (wet-process methyllene blue method) at the wavelength of methylene blue (MB) of $664 \mathrm{~nm}$.

\section{Results and discussion}

Table 2 shows a comparison of the film deposition rates for DC reactive magnetron sputtering and the highrate low-temperature sputtering used in the present research. The deposition conditions used for both, such as power density input to the target, were the same. High-rate low-temperature sputtering yielded approximately 15 times the deposition rate of DC reactive magnetron sputtering. In DC reactive magnetron sputtering, since the reactive gas uses $\mathrm{O}_{2}$, the target surface oxidizes as the flow ratio of $\mathrm{O}_{2}$ in the deposition process increases. Therefore, a transition region exists in which the sputter ratio is reduced and deposition rate suddenly decreases. In the case of the high-rate low-temperature sputtering, on the other hand, by carrying out the ultrathin metal film deposition and film oxidation processes separately, oxidation of the target is prevented. Therefore, no reduction in the deposition rate is observed, and there is almost no reduction in the sputter ratio. In other words, ultimately the same metal compound film as for the DC reactive magnetron sputtering is obtained, however, the deposition process is thin film carried out with the target surface in its metal state. Thus, it is possible to carry out high rate deposition at the same rate as metal film deposition.

Fig. 2 shows the x-ray diffraction (XRD) pattern from a $\mathrm{TiO}_{2}$ thin film made by high-rate low-temperature sputtering with the substrate unheated. Although the substrate was not heated, the only peak observed was that 


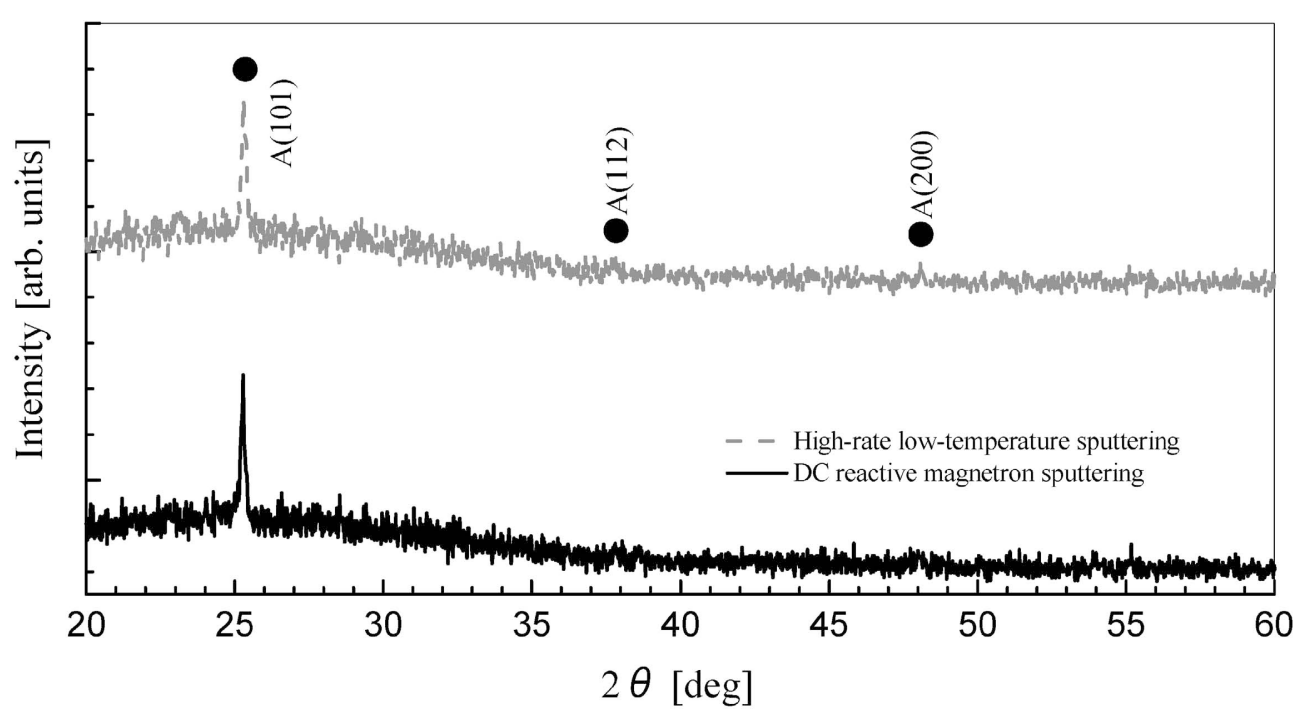

Fig. $2 \mathrm{TiO}_{2}$ thin films x-ray diffraction patterns.

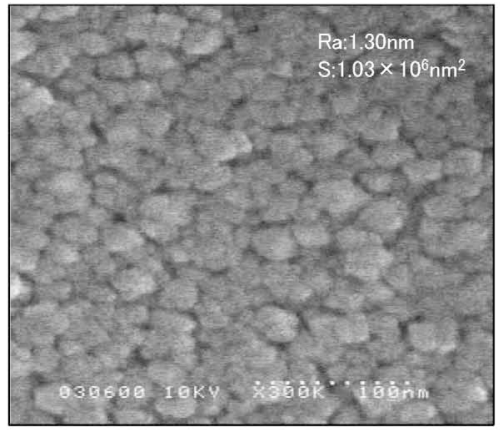

(a) DC reactive magnetron sputtering

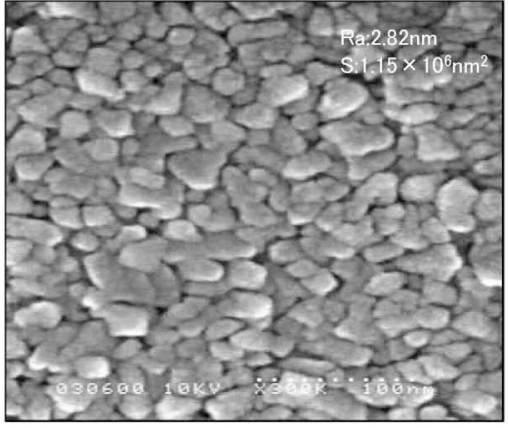

(b) High-rate low-temperature sputtering

Fig. $3 \mathrm{TiO}_{2}$ thin films surface SEM micrographs.

Table 3 Lattice constant and axis ratio of $\mathrm{TiO}_{2}$ films.

\begin{tabular}{|c|c|c|c|}
\hline \multirow{2}{*}{$\begin{array}{c}\text { Deposition } \\
\text { techniques }\end{array}$} & \multirow{2}{*}{$\begin{array}{c}\begin{array}{c}\text { High-rate } \\
\text { low-tempera- } \\
\text { ture sputtering }\end{array} \\
\mathrm{S} 1\end{array}$} & \multicolumn{2}{|c|}{$\begin{array}{c}\text { DC reactive magnetron } \\
\text { sputtering }\end{array}$} \\
\hline & & S2 & ASTM card \\
\hline $\mathrm{a}[\AA]$ & 3.920 & 3.920 & 3.780 \\
\hline c $[\AA]$ & 9.630 & 9.512 & 9.490 \\
\hline $\mathrm{a} / \mathrm{c}$ & 0.394 & 0.398 & 0.398 \\
\hline
\end{tabular}

associated with anatase centered on the peak derived from $2 \theta=25.2^{\circ}$ anatase (101). It was thus verified that they were anatase polycrystals oriented along (101) In addition, the XRD pattern from $\mathrm{TiO}_{2}$ thin film fabricated using DC reactive magnetron sputtering, representing the reference sample, was also verified to include anatase polycrystals based on the observation of the anatase peak. The films produced with high-rate low-temperature sputtering showed a peak intensity that was slightly smaller relative to the reference sample. These results and observed diffraction line positions agree well with those of the diffraction lines of anatase polycrystals described in the corresponding ASTM card. Table 3 shows the results of the calculation of interplanar distance $d$ using the Bragg formula, $2 d \sin \theta=n \lambda$ (where $n$ is an integer) from the position of each diffraction line shown in Fig. 2. The lattice constant of the $\mathrm{TiO}_{2}$ thin film was calculated from the following relation between the lattice constant and interplanar distance $d$ :

$$
\frac{1}{d^{2}}=\frac{h^{2}+k^{2}}{a^{2}}+\frac{l^{2}}{c^{2}}
$$

Here, $\theta$ is the diffraction angle, $\lambda$ is the wavelength of the $\mathrm{X}$-rays used; the $\mathrm{X}$-ray wavelength used in the present research is $\lambda=1.54056[\AA]$. Growth along the C-axis of the $\mathrm{TiO}_{2}$ thin film formed by the high-rate low-temperature sputtering is weak compared to the $\mathrm{TiO}_{2}$ thin film formed by DC reactive magnetron sputtering. However, it is close to the $\mathrm{TiO}_{2}$ lattice constant a described in the ASTM card ( $a=3.780 \AA, c=9.490 \AA, a / c=0.398)$.

Surface SEM images of the $\mathrm{TiO}_{2}$ thin films are shown in Fig. 3. The $\mathrm{TiO}_{2}$ thin film formed by the high-rate low-temperature sputtering shows grains approximately $10 \sim 20 \mathrm{~nm}$ in size with a very porous construction, and with a grain-to-grain spacing of roughly $5 \mathrm{~nm}$. The surface is coarser compared to the $\mathrm{TiO}_{2}$ thin film formed by DC magnetron sputtering, and grain growth can be observed. All $\mathrm{TiO}_{2}$ thin films were anatase polycrystalline thin films, and the average grain size could be determined from the half width of the diffraction peak of the anatase (101) surface.

The average grain size $D$ may be expressed, according 


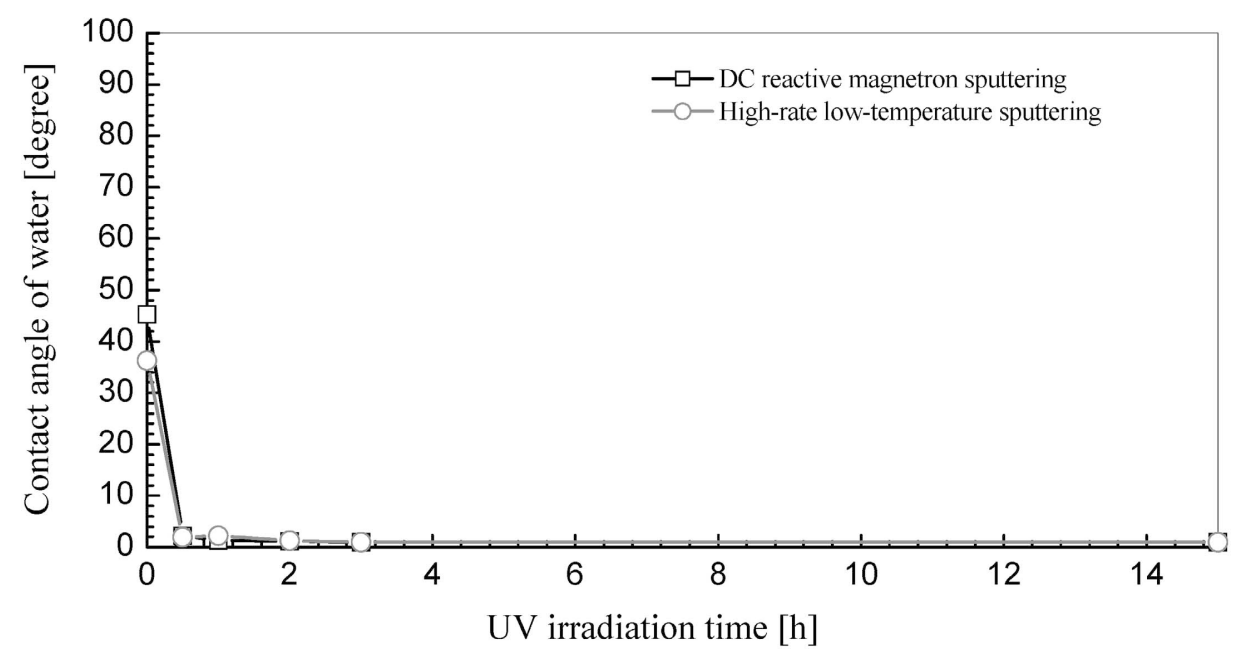

Fig. 4 Photoinduced hydrophilic conversion properties of $\mathrm{TiO}_{2}$ thin films.

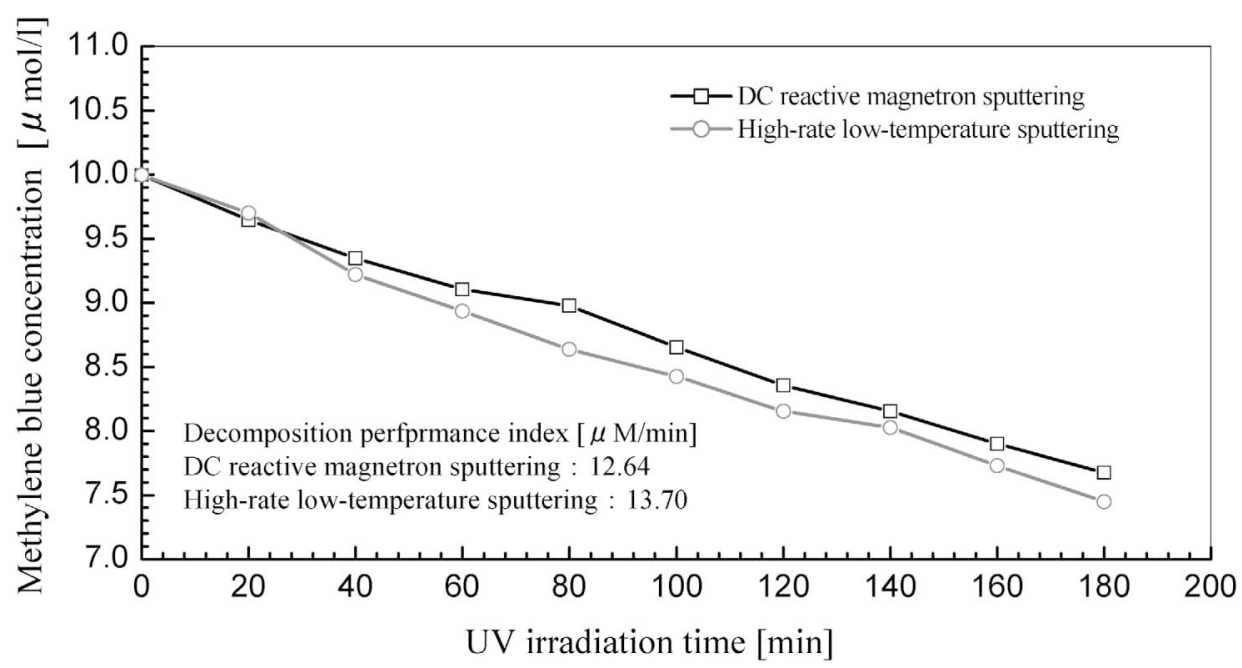

Fig. $5 \mathrm{TiO}_{2}$ thin film oxidative decomposition properties.

Table 4 Average grain size of $\mathrm{TiO}_{2}$ films.

\begin{tabular}{lcccc}
\hline \hline \multicolumn{1}{c}{ Deposition techniques } & plane & $\beta_{1 / 2}$ & $2 \theta(101)$ & $\begin{array}{c}\text { glain size } \\
\text { D [nm] }\end{array}$ \\
\hline $\begin{array}{l}\text { High-rate low-temperature } \\
\text { sputtering }\end{array}$ & 101 & 0.418 & 25.28 & 19.48 \\
$\begin{array}{l}\text { DC reactive magnetron } \\
\text { sputtering }\end{array}$ & 101 & 0.441 & 25.22 & 18.46 \\
\hline
\end{tabular}

to Scherrer's formula, in terms of the half width $\beta_{1 / 2}$ of the diffraction peak, the $\mathrm{x}$-ray wavelength $\lambda$, and diffraction angle $\theta$ :

$$
D=\frac{0.9 \lambda}{\beta_{1 / 2} \times \cos \vartheta}
$$

Using the diffraction pattern in Fig. 2 as well as (2), the calculated average grain sizes are shown in Table 4. No clear distinction could be made between the different deposition methods. These results are similar to those obtained using SEM as shown in Fig. 3. The contact angle of water droplets of $\mathrm{TiO}_{2}$ thin films produced by high-rate low-temperature sputtering prior to UV radiation was approximately $40^{\circ}$; and hydrophilicity was not observed.
Fig. 4 shows the relation between UV irradiation time and changes in contact angle when UV irradiation was performed after leaving the samples in the dark for 24 hours or more. Excellent hydrophilicity was observed after the UV irradiation. After one hour of UV irradiation, the contact angle was reduced to around $5^{\circ}$, yielding a hydrophilic state. Also, based on the contact angle of around $5^{\circ}$ for the reference sample, demonstrating hydrophilicity, the results show that $\mathrm{TiO}_{2}$ thin films formed in the present research possess the same characteristics as the reference samples. Fig. 5 shows the wetprocess methyllene blue mothod results of the films made by high-rate low-temperature sputtering. We reduced the concentration of methylene blue with increasing UV irradiation time, demonstrating oxidative decomposition activity. In this evaluation method, a decomposition activity index was used as an index to represent photocatalytic degradation characteristics. ${ }^{14)}$ The decomposition activity index is the slope of least squares linear approximation of 4 points, obtained by choosing four points at which changes in the concentration of methylene blue versus UV irradiation time experience the largest movements in the linear range. A large value for the index in- 
dicates that a large amount of organic matter can be decomposed on a per unit time basis. The decomposition activity index of the thin film was a high $13.70[\mu \mathrm{M} / \mathrm{min}]$, and showed the same properties as the $\mathrm{TiO}_{2}$ thin film used as the reference sample.

\section{Conclusion}

In summary Future technological challenges of functional oxide layers include the development of methods of reducing deposition temperature below current levels, system simplification, throughput improvement, and cost reduction. For such practical needs, we used the high-rate low-temperature sputtering and were successful in forming $\mathrm{TiO}_{2}$ thin films possessing deposition rates at the same level as the metal film deposition times, with photocatalyst activity in the unheated state. The $\mathrm{TiO}_{2}$ thin film thus produced shows the same photocatalyst activity as the $\mathrm{TiO}_{2}$ thin film made by DC reactive magnetron sputtering. Applications of the present technology for production are expected by carrying out further quality improvements, such as structural optimization, including evaluations under actual environmental conditions and devices.

\section{Acknowledgements}

Portions of the present research were carried out by research grants from the 2006/2007 Ministry of Education, Science, Sports and Culture, Grant-in-Aid for Encouragement of Young Scientists B (No. 18750553), the
2007/2008 Miyazaki Prefecture Regional Program for the Strategic Promotion of Science and Technology, and the Nippon Sheet Glass Foundation for Materials Science and Engineering in 2007. We are thankful to all those who participated.

\section{Reference}

1) K. Honda and A. Fijishima: Nature., 238 (1972) 37.

2) T. Kawai and T. Sakata: Nature., 286 (1980) 474.

3) A. Nakajima, S. Koizumi, T. Watanabe, K. Hashimoto: Langmuir., 16 (2000) 474.

4) M. Machida, K. Norimoto, T. Watanabe, K. Hashimoto, A. Fujishima: J. Mater. Sci., 34 (1999) 2569.

5) K. Miyashita, S. Kuroda, T. Ubukata, T. Ozawa, H. Kubota: J. Mater Sci., 36 (2001) 3877.

6) M. Yamagishi, S. Kuruki, P. K. Song, Y. Shigesato: Thin Solid Films., 442 (2003) 227.

7) P. K. Song, Y. Irie, Y. Sato and Y. Shigesato: Jpn. J. Appl. Phys., Vol. 43, No. 3A (2004) L358.

8) P. K. Song, Y. Irie, S. Ohno, Y. Sato and Y. Shigesato: Jpn. J. Appl. Phys., Vol. 43, No. 4A (2004) L442.

9) P. K. Song, Y. Irie, Y. Sato and Y. Shigesato: Thin Solid Films., 496 (2006) 121.

10) D. Noguchi, Y. Kawamata, T. Nagatomo: Jpn. J. Appl. Phys., Vol. 42, Part 1, No. 8 (2003) 5255.

11) D. Noguchi, Y. Kawamata, T. Nagatomo: Jpn. J. Appl. Phys., Vol. 43, No. 4A (2003) 1581.

12) D. Noguchi, Y. Kawamata, T. Nagatomo: Jpn. J. Appl. Phys., Vol. 43, No. 7A (2004) 4351.

13) D. Noguchi: Sshibaura Mechatoronics Technical report, No. 35 (2002) 20 [in Japanese].

14) Y. Katukawa, S. Abe: Proc. 8th Photocatalyst Symposium, Tokyo, Japan, Vol. 6 (2001) D-01. 